\title{
A chemical toxicity sensor based on the electrochemiluminescence quantification of apurinic/apyrimidinic sites in double-stranded DNA monolayer
}

\author{
Rui Feng ${ }^{\mathrm{a}, \mathrm{b}}$, Gang Liang ${ }^{\mathrm{a}}$, Liang-Hong Guo ${ }^{\mathrm{a}, \mathrm{b}, \mathrm{c}, *}$, Yi-Ping Wu ${ }^{\mathrm{d}}$ \\ a State Key Laboratory of Environmental Chemistry and Ecotoxicology, Research Center for Eco-Environmental Sciences, Chinese Academy of Sciences, 18 \\ Shuangqing Road, P.O. Box 2871, Beijing 100085, China \\ ${ }^{\mathrm{b}}$ College of Resources and Environment, University of Chinese Academy of Sciences, Beijing 100049, China \\ ${ }^{\mathrm{c}}$ Institute of Environment and Health, Jianghan University, Wuhan, Hubei 430056, China \\ ${ }^{\mathrm{d}}$ Ministry of Education Key Laboratory of Resource Chemistry, Shanghai Key Laboratory of Rare Earth Functional Materials, Department of Chemistry, \\ Shanghai Normal University, Shanghai 200234, China
}

\section{A R T I C L E I N F O}

\section{Article history:}

Received 16 November 2016

Received in revised form 13 March 2017

Accepted 4 April 2017

Available online 6 April 2017

\section{Keywords:}

Apurinic/apyrimidinic sites

Aldehyde reactive probe

Electrochemiluminescence

Toxicity

DNA biosensor

\begin{abstract}
A B S T R A C T
A new chemical toxicity sensor was developed based on the electrochemiluminescence (ECL) quantification of apurinic/apyrimidinic sites (AP sites) in a DNA monolayer with a covalent aldehyde reactive probe (ARP). In the sensor, a uracil-containing DNA duplex was first immobilized on a gold electrode by self-assembly. The duplex was then reacted with uracil-DNA glycosylase (UDG) to convert uracils into AP sites. ARP was employed to tag the AP site with a biotin. After reacting with a ruthenium complex labeled streptavidin, ECL was measured for quantitative analysis. The DNA monolayer was characterized by cyclic voltammetry, electrochemical impedance spectroscopy and chronocoulometry, and its density was measured to be $2.89 \times 10^{-12} \mathrm{~mol} / \mathrm{cm}^{2}$. Characterization of the reaction product between ARP and DNA AP sites in solution by nondenaturing polyacrylamide gel electrophoresis and mass spectrometry confirmed successful biotinylation. ECL intensity of the labeled DNA monolayer on the electrode was found to correlate with the number of AP sites, and the detection limit was estimated to be about 1 lesion in 512 DNA bases, which meant that $8.5 \mathrm{fmol}$ AP bases on the electrode were detected. ECL response of the DNA monolayers containing either 8-oxodGuo or methylated bases was very low, indicating that ARP-based AP sites detection method was highly selective. The sensor successfully detected the AP sites in normal DNA induced by methylmethane sulfonate, a carcinogenic chemical. The novel combination of covalent probe and ECL measurement in a sensor configuration therefore provides unique advantages in selectivity and sensitivity, and can be potentially employed in the screening of chemicals for their genetic toxicity.
\end{abstract}

(C) 2017 Elsevier B.V. All rights reserved.

\section{Introduction}

Nucleic acids can potentially experience a variety of damage, including strand break, deamination, depurination/depyrimidines, base oxidation, and base modification [1]. One of the most abundant lesions in genomic DNA is apurinic/apyrimidinic site (AP site), which is the lesion formed by loss of a nucleobase after cleavage of the $\mathrm{N}$-glycosylic bond that connects a purine or pyrimidine base to the deoxyribose sugar [2]. AP sites can be generated under the

\footnotetext{
* Corresponding author at: State Key Laboratory of Environmental Chemistry and Ecotoxicology, Research Center for Eco-Environmental Sciences, Chinese Academy of Sciences, 18 Shuangqing Road, P.O. Box 2871, Beijing 100085, China.

E-mail address: LHGuo@rcees.ac.cn (L.-H. Guo).
}

action of various physical and chemical agents including UV and ionizing radiation, chemical oxidants, and chemical mutagens and carcinogens [3]. AP sites can also be generated from spontaneous depurination. For a mammalian cell, which grows with a generation time of $20 \mathrm{~h}, 12,000$ purines can be lost from the DNA in each cell generation due to hydrolysis [4]. Excision of altered nucleotides by glycosylases is another mechanism for the generation of AP sites [5]. Among these glycosylases, uracil-DNA glycosylase (UDG) is the most efficient enzyme, and is responsible for the removal of most uracil bases from DNA (Fig. S-1). AP sites are normally repaired by apurinic/apyrimidinic endonucleases during the process of base excision repair (BER). However, some AP sites may evade the repair process and become permanent mutation sites after DNA replication and transmission. Accumulation of these mutation sites has 
significant impacts on the premature aging as well as occurrence of some serious diseases such as cancers.

Considering the significance of AP sites in molecular biology and carcinogenesis, it is highly desirable to develop analytical methods to identify and quantify AP sites in DNAs as well as to screen chemicals for their potential genetic toxicity. A variety of analytical methods have been developed for the determination and quantification of AP sites in DNA, including ${ }^{32} \mathrm{P}$-postlabelling assay, LC-MS/MS and ELISA assay [6]. ${ }^{32} \mathrm{P}$-postlabelling assay is sensitive and selective, but the process uses radioactive materials, and is also labor intensive and tedious. LC-MS/MS is accurate and reliable, but requires complex sample pretreatment and expensive equipment. ELISA assay is simple to operate, but the antibodies used in the assay to recognize AP sites may lack specificity. More recently, research work has focused on bioassays and biosensors employing structure-based chemical probes for AP site recognition and detection, which are either non-covalent or covalent reaction type probes $[7,8]$. After the formation of an AP site in DNA, a cavity is created that can readily accommodate a small molecule with complementary shape and binding forces. Therefore, a chemical probe with signal-producing functionality can be designed to bind non-covalently to the AP site. Teramae's group has designed and synthesized a series of environmentally sensitive fluorescent probes which bind selectively to AP sites in ds-DNA. The binding was manifested by either fluorescence quenching or enhancement [9-14]. Wu et al. reported an AP site selective fluorescent probe, sanguinarine with a large emission shift [15].

AP sites exist in different forms in equilibrium, including the closed-ring hemiacetal and open-chain aldehyde. The latter is chemically more reactive, and is the popular target of most covalent chemical probes in AP site detection. A biotin-containing aldehydereactive probe (ARP, Fig. S-2) was first reported by Kubo et al., which consisted of a nucleophilic $O$-substituted hydroxylamine to react covalently with the AP aldehyde [16]. Atamna et al. employed ARP to measure AP sites in living cells. The probe was found to penetrate the plasma membrane and react with the AP sites in DNA, which was then quantified by colorimetry after labeling with avidin-HRP [17]. Tanaka et al. found that ARP could also be used to quantify the AP sites in RNA with a detection limit of $10 \mathrm{fmol}$ [18]. Kojima et al. improved the reaction rate of the probe by incorporating a hydrophobic and a hydrophilic residue into an aminooxy group [19]. In addition to the biotin tags described above, fluorescent dye-hydroxylamine conjugates were also synthesized as covalent probes, which were measured directly for AP site detection [20-22]. In a different approach, osmium tetroxide-2,2'-bipyridine was employed as an electrochemical probe of AP sites, which reacts covalently with the unpaired thymine bases in damaged DNA [23]. Furthermore, although a few chemical toxicity sensors based on the detection of oxidized or methylated DNA bases have been developed [24-36], so far there has been no report on the study of toxicity sensors based on AP site detection.

Electrochemiluminescence (ECL) is light emission following an electrochemical reaction triggered at the surface of an electrode. Due to the distinctive separation of excitation source (electrons) and detection signal (photons), ECL is intrinsically highly sensitive. The high sensitivity, coupled with ease of control and relatively simple instrumentation has enabled its wide application in biosensing systems $[37,38]$. In this work, we aimed to develop a chemical toxicity sensor based on the detection of AP sites in DNA with high selectivity and sensitivity which can be used for the screening of chemical toxicity. The sensor takes advantage of ARP as a covalent biotinylation tag which offers much higher selectivity than non-covalent probes toward AP sites. Ruthenium complex labeled streptavidin is then linked with biotin for the highly sensitive ECL detection. The novel combination of covalent probe and ECL measurement in a biosensor configuration can provide unique advantages in terms of selectivity, sensitivity, speed and simplicity. This sensor can be used to screen for chemicals that can cause direct damage to DNAs on the sensor surface after the sensor is exposed to the chemical.

\section{Experimental section}

\subsection{Reagents and materials}

Oligonucleotides, $5 \times$ TBE buffer, 30\% acrylamide, ammonium persulfate (APS) tetramethylethylenediamine (TEMED) and low MW DNA marker-A were purchased from Sangon Inc. (Shanghai, China). ARP was purchased from Dojindo Molecular Technologies, Inc. (Dojindo, Japan). Ruthenium bis(2,2'-bipyridine)(4-methyl-4'carboxyl-2,2'-bipyridine) $\mathrm{N}$-hydroxysuccinimide ester (Ru-NHS), streptavidin, bicinchoninic acid protein assay reagent (BCA reagent), tris(2-carboxyethyl) phosphine hydrochloride (TCEP), 6-Mercapto-1-hexanol (MCH), tripropylamine (TPA), ethylenediaminetetraacetic acid (EDTA), methylmethane sulfonate (MMS), $\mathrm{AgNO}_{3}$, methanol and $\mathrm{NaOH}$ were from Sigma-Aldrich (St. Louis, MO, USA). UDG and $1 \times$ UDG buffer ( $20 \mathrm{mM}$ tris-HCl, $1 \mathrm{mM}$ EDTA, 1 mM DL-dithiothreitol, pH 8.0), endonuclease IV, human alkyladenine DNA glycosylase (hAAG) and $1 \times$ thermoPol buffer $(10 \mathrm{mM}$ $\mathrm{KCl}, 10 \mathrm{mM}\left(\mathrm{NH}_{4}\right)_{2} \mathrm{SO}_{4}, 20 \mathrm{mM}$ tris- $\mathrm{HCl}, 2 \mathrm{mM} \mathrm{MgSO}_{4}, 0.1 \%$ triton $\mathrm{X}-100, \mathrm{pH} 8.8$ ) were purchased from New England Biolabs (Ipswich, MA, USA). Nicotinic acid (99.5\%), anthranilic acid (99.5\%) and diammonium hydrogen citrate $(99 \%)$ were purchased from Fluka Analytical (Buchs, Switzerland). Buffers used in this work were as follows: DNA hybridization solution $(2 \times$ SSC buffer, $0.3 \mathrm{M}$ $\mathrm{NaCl}, 30 \mathrm{mM}$ sodium citrate, $\mathrm{pH}$ 7.0), DNA immobilization buffer (I-buffer, $10 \mathrm{mM}$ tris-HCl, $1 \mathrm{mM}$ EDTA, $1.0 \mathrm{M} \mathrm{NaCl}, 1 \mathrm{mM}$ TCEP, $\mathrm{pH}$ 8.0), buffer for ECL measurement (E-buffer, 0.2 M TPA, $0.1 \mathrm{M} \mathrm{NaCl}$, $0.15 \mathrm{M} \mathrm{NaH}_{2} \mathrm{PO}_{4}, 0.1 \%$ triton X-100, $\mathrm{pH}$ 7.4). TCEP was used to cleave disulfides and was prepared on the day of use. All other chemicals were of analytical reagent grade and used without further purification. All solutions were prepared with high-purity water from a Millipore Milli-Q Biocel (Boston, MA, USA). The sequences of oligonucleotides are shown in Table 1.

\subsection{Streptavidin-Ru synthesis}

Streptavidin was labeled with Ru-NHS by following the published procedure [39]. Ru-NHS was dissolved in dry dimethylformamide and then transferred to a streptavidin solution $(200 \mu \mathrm{L}$, $10 \mathrm{mg} / \mathrm{mL})$ in $100 \mathrm{mM}$ sodium phosphate buffer, pH $7.5(\mathrm{Ru}-$ $\mathrm{NHS} /$ streptavidin ratio $=10: 1$ ) [40]. After $4 \mathrm{~h}$ mixing in the dark at $25^{\circ} \mathrm{C}$, unreacted Ru-NHS was separated from the protein on a Thermo Scientific Pierce polyacrylamide desalting column with a 6000 MW cutoff (Waltham, MA, USA). The labeled streptavidin was finally exchanged into $20 \mathrm{mM}$ sodium phosphate buffer, $\mathrm{pH}$ 7.5. The

Table 1

Sequences of the oligonucleotides used in the study.

\begin{tabular}{|c|c|}
\hline Oligonucleotide & Sequence \\
\hline Oligo 1 (no uracil base) & $\begin{array}{l}5^{\prime}-\mathrm{SH}^{-\mathrm{C}_{6}} \text {-TTT TTT TCT CCA CTG AAA CAT ACT } \\
\text { CCA-3' }^{\prime}\end{array}$ \\
\hline Oligo 2 (complementary) & 5'-TGG AGT ATG TTT CAG TGG AGA-3' \\
\hline Oligo 3 ( 1 uracil base) & $\begin{array}{l}\text { 5'-SH-C } 6 \text {-TTT TTT TCT CCA CUG AAA CAT ACT } \\
\text { CCA-3' }\end{array}$ \\
\hline Oligo 4 ( 3 uracil bases) & $\begin{array}{l}5^{\prime}-\mathrm{SH}^{-\mathrm{C}_{6}} \text {-TTT TTT UCT CCA CUG AAA CAU ACT } \\
\text { CCA-3' }^{\prime}\end{array}$ \\
\hline Duplex 1 & Hybridized oligonucleotides of Oligo 1 and Oligo 2 \\
\hline Duplex 2 & Hybridized oligonucleotides of Oligo 3 and Oligo 2 \\
\hline Duplex 3 & Hybridized oligonucleotides of Oligo 4 and Oligo 2 \\
\hline Duplex G & $\begin{array}{l}\text { Hybridized oligonucleotides of } 5^{\prime}-\mathrm{SH}-\mathrm{C}_{6}-\mathrm{CTC} \text { CTC } \\
\text { CCC CAT CTC CTC CCA GTC C-3' and 3'-GAG GAG } \\
\text { OGG OTA GAG GAG OGT CAO G-5' }(\mathrm{O}=8 \text {-oxodGuo })\end{array}$ \\
\hline
\end{tabular}


labeled protein was characterized by measuring its UV-vis absorption spectra on an Agilent UV-vis spectrophotometer (Santa Clara, CA, USA). As shown in Fig. S-3, the spectrum showed characteristic peaks for Ru-complex at $450 \mathrm{~nm}$ and $286 \mathrm{~nm}$ and protein at $286 \mathrm{~nm}$. Ru content in the protein was calculated based on the absorbance at $450 \mathrm{~nm}$, and protein concentration was determined using the BCA reagent. The ratio of $\mathrm{Ru} /$ streptavidin was found to be 5.87: 1 .

\subsection{Electrode modification and characterization}

Oligonucleotide hybridization was performed in $2 \times$ SSC buffer on a Biometra-Gradient thermocycler (Goettingen, Germany). The mixture solution of two complementary oligonucleotides $(100 \mu \mathrm{M}$ each) was heated at $95^{\circ} \mathrm{C}$ for $5 \mathrm{~min}$, and then $75^{\circ} \mathrm{C}$ for $5 \mathrm{~min}$, finally slowly cooled down to room temperature. The prepared duplex solution $(50 \mu \mathrm{M})$ was stored at $4{ }^{\circ} \mathrm{C}$ for further use.

Gold electrode modification was performed according to a reported procedure [41]. Briefly, a gold electrode ( $2 \mathrm{~mm}$ in diameter, CH Instruments Inc. Austin, TX, USA,) was polished on a microcloth with $0.05 \mu \mathrm{m}$ alumina suspension and washed ultrasonically in ethanol and Milli-Q water for 1 min separately. Then, electrochemical cleaning was performed on a CHI 830D electrochemical workstation (Shanghai $\mathrm{CH}$ Instruments Co., Shanghai, China) in $0.5 \mathrm{M} \mathrm{H}_{2} \mathrm{SO}_{4}$ by applying a positive potential of $2.0 \mathrm{~V}$ for $5 \mathrm{~s}$, followed by a negative potential of $-0.35 \mathrm{~V}$ for $10 \mathrm{~s}$. Next, repetitive cyclic voltammetry (CV) scans were conducted in $0.5 \mathrm{M} \mathrm{H}_{2} \mathrm{SO}_{4}$ within a potential window between -0.3 and $1.55 \mathrm{~V}$ for 10 cycles at a scan rate of $4 \mathrm{~V} / \mathrm{s}$ and for 2 cycles at a scan rate of $0.1 \mathrm{~V} / \mathrm{s}$, respectively. Finally, the electrode was rinsed with Milli-Qwater and dried in $\mathrm{N}_{2}$ stream.

The stored oligonucleotide duplex solution $(50 \mu \mathrm{M})$ was diluted with I-buffer. DNA immobilization was performed by applying $2.0 \mu \mathrm{M}$ duplex on a freshly cleaned gold electrode surface and incubating for $48 \mathrm{~h}$ at room temperature. The electrode was then washed with plenty of $20 \mathrm{mM}$ tris buffer ( $\mathrm{pH} 7.4$ ). Subsequently, the electrode was treated with $10 \mathrm{mM} \mathrm{MCH}$ for $2 \mathrm{~h}$ to remove weakly adsorbed duplex and block empty sites. Electrochemical impedance spectroscopy (EIS) measurements were conducted in a solution of $0.1 \mathrm{M}$ sodium phosphate $(\mathrm{pH} 7.0)$ containing $5 \mathrm{mM}\left[\mathrm{Fe}(\mathrm{CN})_{6}\right]^{3-/ 4-}$ on a $\mathrm{CHI} 660 \mathrm{~B}$ electrochemical workstation (also from Shanghai $\mathrm{CH}$ Instruments $\mathrm{Co}$.) in a frequency range from $0.1 \mathrm{~Hz}$ to $10^{5} \mathrm{~Hz}$. The bias potential was $210 \mathrm{mV}$ vs. $\mathrm{Ag} / \mathrm{AgCl}$. Chronocoulometry (CC) was carried out in a solution of $\mathrm{Ru}\left(\mathrm{NH}_{6}\right)_{3}{ }^{3+} / 10 \mathrm{mM}$ tris buffer ( $\mathrm{pH} 8.0$ ) on the CHI 830D electrochemical workstation with a pulse period of $250 \mathrm{~ms}$ and pulse width of $700 \mathrm{mV}$.

\subsection{AP site generation, labeling and characterization}

DNA modified gold electrodes were incubated with $4 \mu \mathrm{L}$ of $0.1 \mathrm{U} / \mu \mathrm{L}$ UDG for $30 \mathrm{~min}$ at $37^{\circ} \mathrm{C}$ to remove uracil bases and generate defined AP sites in the duplex [42]. A $4 \mu$ L solution of $10 \mathrm{mM} \mathrm{ARP}$ in $10 \mathrm{mM}$ tris- $\mathrm{HCl}$ ( $\mathrm{pH} \mathrm{8.0)}$ was then added into the above solution, and the electrode was incubated for another hour at $37^{\circ} \mathrm{C}$ to tag the AP sites with biotin [43]. Subsequently, streptavidin-Ru $(0.2 \mu \mathrm{M}$, $4 \mu \mathrm{L}$ ) was added and incubated for $30 \mathrm{~min}$ at $25^{\circ} \mathrm{C}$. The electrode was then washed thoroughly before ECL measurement.

AP site generation was verified by characterizing the reaction product of $50 \mu \mathrm{M}$ Duplex 3 with $5 \mathrm{U} / \mu \mathrm{L}$ UDG and $0.5 \mathrm{U} / \mu \mathrm{L}$ endonuclease IV enzymes in $10 \mathrm{mM}$ tris- $\mathrm{HCl}(\mathrm{pH} 8.0)$ by nondenaturing polyacrylamide gel electrophoresis (PAGE) [44]. The experiments were conducted on a Bio-Rad 165-8001 Mini-ProteanTetra electrophoresis system (Hercules, CA, USA). Nondenaturing gels were prepared with $30 \%$ acrylamide (v/v), $12 \% 5 \times$ TBE buffer $(450 \mathrm{mM}$ tris-borate, $10 \mathrm{mM}$ EDTA, pH 8.3), 10\% APS (w/v) and 0.04\% TEMED $(\mathrm{v} / \mathrm{v})$. The gels were run for $80 \mathrm{~min}$ at $120 \mathrm{~V}$. The bands were stained for $10 \mathrm{~min}$. The gels were then placed into $0.1 \% \mathrm{AgNO}_{3}$ shocking for
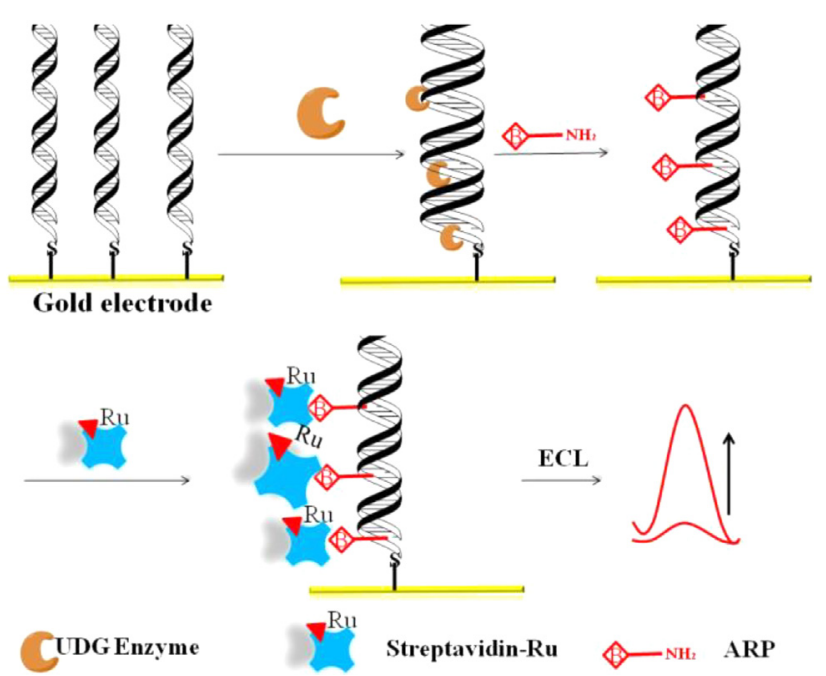

CDGEnzyme

Streptavidin-Ru

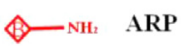

Scheme 1. Illustration of the ARP-based ECL biosensor for the detection of DNA AP sites.

10 min to inset $\mathrm{Ag}^{+}$into DNA and were stained with $0.4 \%$ methanol in $1.2 \% \mathrm{NaOH}$ solution for $15 \mathrm{~min}$. The gels were scanned and the bands were quantitated using an UMAX PowerLook 2100XL-USB image scanner (Dallas, TX, USA).

AP site labeling with ARP was verified by characterizing the reaction product of $50 \mu \mathrm{M}$ Oligo 4 with $5 \mathrm{U} / \mu \mathrm{L}$ UDG and $5 \mathrm{mM}$ ARP in $10 \mathrm{mM}$ tris- $\mathrm{HCl}$ ( $\mathrm{pH} \mathrm{8.0)}$ by matrix-assisted laser desorption/ionization time of flight mass spectrometry (MALDI-TOF MS) and PAGE. A Bruker Autoflex III Smartbeam mass spectrometer (Bruker Daltonics, Bremen, Germany) was used for MALDI-TOF MS analysis, equipped with a nitrogen laser operating at $337 \mathrm{~nm}$ and an ion source operating in delayed extraction mode by following a reported method [45]. In the experiment, AA/NA/DHC matrix solution was prepared by dissolving $3.0 \mathrm{mg}(0.02 \mathrm{mmol})$ of AA and $1.5 \mathrm{mg}(0.01 \mathrm{mmol})$ of NA in a $80 \mu \mathrm{L}$ solution of acetonitrile/ultrapure water $(5: 3, v / v)$ and adding $6 \mu \mathrm{L}$ of $10 \mathrm{mM}$ DHC. The final molar ratio of AA, NA, and DHC was 2:1:0.006. The digest solution $(1.0 \mu \mathrm{L})$ was mixed with $1.0-1.5 \mu \mathrm{L}$ matrix solution and deposited onto a 384/400 $\mu \mathrm{m}$ Bruker Daltonics Anchor Chip MALDI target plate (Billerica, MA, USA) immediately.

\subsection{ECL measurement}

ECL measurement was performed on the CHI $660 \mathrm{~B}$ electrochemistry analyzer by placing the DNA-modified gold electrode in E-buffer, using a Pt flag counter electrode and a $\mathrm{Ag} / \mathrm{AgCl}(3 \mathrm{M} \mathrm{KCl})$ reference electrode. The ECL signal was collected with a H930603 photomultiplier tube (PMT, Hamamatsu, Honshu, Japan) placed directly under the transparent electrochemical cell. Both the cell and PMT were enclosed in a light-tight box. The voltage output of the PMT was sent to the auxiliary signal recording port on the $\mathrm{CHI}$ $660 \mathrm{~B}$ analyzer.

\section{Results and discussion}

Scheme 1 illustrates the principle of the ECL biosensor for the detection of DNA AP sites. Thiol-terminated, uracil-containing oligonucleotide duplex is immobilized on a gold electrode surface by self-assembly. UDG removes the base from uracil and thus generates an AP site. ARP is employed to tag the AP site with a biotin by its reaction with an active aldehyde group in the ring opened AP site. Ru complex labeled streptavidin is then linked to the biotin on DNA for ECL signal detection. 


\subsection{Characterization of DNA films immobilized on gold electrodes}

CV, EIS and CC were employed to characterize DNA films immobilized on gold electrodes. $\mathrm{CV}$ was performed in a solution of $1 \mathrm{mM} \mathrm{K}_{3}\left[\mathrm{Fe}_{3}(\mathrm{CN})_{6}\right]$ containing $0.1 \mathrm{M} \mathrm{KCl}$. As shown in Fig. S-4A, well-defined voltammetric response was obtained on a bare gold electrode, corresponding to reversible electrochemical reaction of $\mathrm{Fe}(\mathrm{CN})_{6}{ }^{3-}$. On Duplex 3-modified electrode, however, the response became much less reversible, as indicated by the broadening of the two peaks and shift of their potentials. This is most likely due to the charge repulsion between $\mathrm{Fe}(\mathrm{CN})_{6}{ }^{3-}$ anion and negatively charged DNA backbone [46]. DNA strands are known to interact with gold via the nitrogen atoms of the bases, thus leading to multiple contacts at gold surfaces [47]. Incubation of the DNA-covered electrode in $\mathrm{MCH}$ removed some weakly adsorbed DNA molecules from the surface, reduced the charge repulsion, and consequently improved the voltammetric response. The $\mathrm{CV}$ results revealed that a film of Duplex 3/MCH was assembled successfully on the gold electrode.

The modified electrodes were also characterized by EIS in $5 \mathrm{mM}\left[\mathrm{Fe}_{3}(\mathrm{CN})_{6}\right]^{3-/ 4-}$. In the EIS response curve, the semicircle portion at high frequencies corresponds to the electron-transfer limited process, and the linear portion at low frequencies represents the diffusion-limited process [48]. Clearly, the bare gold electrode produced a very small semicircle, implying a very fast electron-transfer process with a diffusion limiting step (Fig. S-4B). After DNA modification, the semicircle became much larger due to slower electron transfer reaction, indicating DNA assembly on the electrode. After incubation with $\mathrm{MCH}$, the resistance $\left(R_{\mathrm{et}}\right)$ of the electrode decreased significantly, suggesting facilitated electrochemical reaction after $\mathrm{MCH}$ adsorption. The EIS results provided more evidence for the successful fabrication of Duplex 3/MCH modified electrodes.

CC of Duplex 3/MCH modified electrodes was carried out in $\mathrm{Ru}\left(\mathrm{NH}_{6}\right)_{3}{ }^{3+}$ to estimate the amount of DNA molecules immobilized on the electrode surface [49]. Typical CC curves are shown in Fig. S4C. Surface density of the DNA on the gold electrode was calculated by using the following equation,

$\Delta \mathrm{Q}=\mathrm{nFA} \Gamma_{0}$

$\Gamma_{\mathrm{DNA}}=\Gamma_{0}(\mathrm{Z} / \mathrm{m})$

where $n$ is the number of electrons in the electrode reaction, $A$ is the area of the working electrode, $\mathrm{m}$ is the number of nucleotides in DNA, $z$ is the charge of the redox probe, and $F=96485 \mathrm{C} / \mathrm{mol}$. Based on the charge obtained from Fig. S-4C, the surface density of Duplex 3 is $2.89 \times 10^{-12} \mathrm{~mol} / \mathrm{cm}^{2}$, which is identical to the published value [50]. Furthermore, the stability of Duplex 3-modified gold electrodes was evaluated by repeated $\mathrm{CC}$ measurements of the same electrode after storage in the tris- $\mathrm{HCl}$ buffer at $25^{\circ} \mathrm{C}$. The electrode retained $98 \%$ surface coverage of Duplex 3 for up to 10 days.

\subsection{Characterization of AP site generation and biotinylation}

After a uracil-contaning DNA film was assembled on the gold electrode, AP sites were generated by reacting with UDG enzyme. To verify AP site generation, a Duplex 3 solution was reacted first with UDG, then with endonuclease IV enzyme which would cleave DNA strands at AP sites. The product was characterized by PAGE. Duplex 1 (no uracil) was used as the control. In the electrophoresis image (Fig. S-5, lane 2), the reaction product with Duplex 1 displayed a major band with a length between $25 \mathrm{bp}$ and $50 \mathrm{bp}$. However, for the Duplex 3 sample, the major band disappeared in the image. Instead, many new bands with much shorter length emerged (lane 3), representing DNA strand breaks. The electrophoresis results confirmed that AP sites were gener-

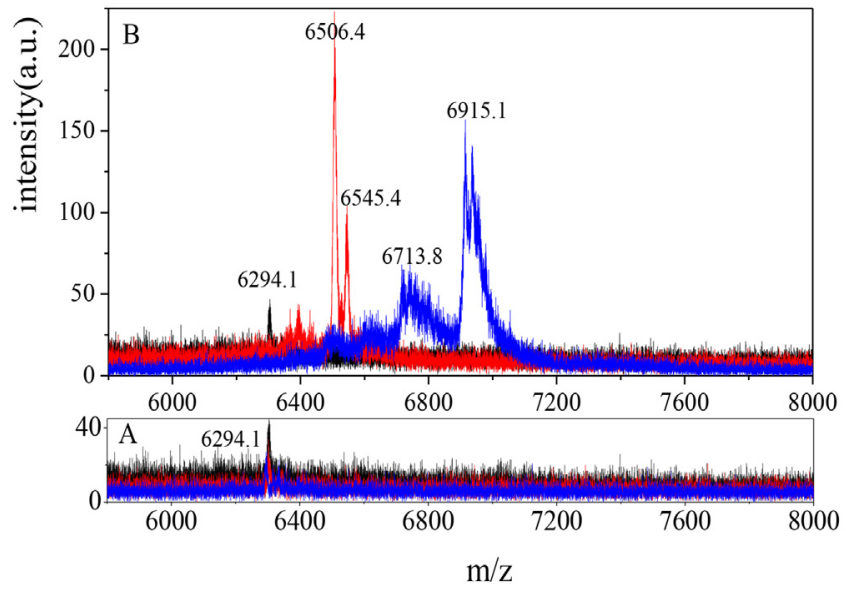

Fig. 1. (A) MALDI-TOF MS of Oligo 1 after incubation with the buffer (blue), UDG (red), and UDG + ARP (black). (B) Mass spectra of $50 \mu \mathrm{M}$ Oligo 1 (black), Oligo 3 (red), and Oligo 4 (blue), after incubation with $5 \mathrm{U} / \mu \mathrm{L}$ UDG and $5 \mathrm{mM}$ ARP in $10 \mathrm{mM}$ tris$\mathrm{HCl}(\mathrm{pH}$ 8.0). (For interpretation of the references to colour in this figure legend, the reader is referred to the web version of this article.)

ated in Duplex 3 by UDG, which were subsequently cleaved by endonuclease IV.

AP site biotinylation was verified by characterizing the solution reaction product by MALDI-TOF MS and PAGE. Because the MALDI-TOF mass spectrometer we used can only detect DNAs of less than 10000 molecular weight, and the duplexes are all over 10000 , single-stranded oligonucleotides were used in this experiment instead of the duplexes. According to previous work, UDG releases uracils from both single-stranded and double-stranded DNA [51,52]. In Fig. 1A, the mass spectra of Oligo 1 (no uracil) showed only one peak $(m / z=6294.1 \mathrm{Da})$ before incubation as well as after its incubation with either UDG alone or UDG and ARP. The absence of any new mass peak after incubation indicates there was no biotinylation. In Fig. 1B, the mass spectra of Oligo 3 (1 uracil) and Oligo 4 ( 3 uracils) after incubation with UDG and ARP are depicted, together with that of Oligo 1. Evidently the primary peaks of Oligo 1, Oligo 3 and Oligo 4 reaction products are $m / z$ 6294.1 Da, 6506.4 Da, and 6915.1 Da, respectively. Meanwhile, secondary peaks of Oligo 3 and Oligo 4 are $m / z 6545.4 \mathrm{Da}$ and $6713.8 \mathrm{Da}$. In theory, after AP site generation and biotinylation, mass spectral peaks should be 6499.4 and 6910.1 for Oligo 3 and Oligo 4, respectively. But, it is already known that oligodeoxynucleotides can form adducts with cations such as $\mathrm{H}^{+}, \mathrm{K}^{+}$and $\mathrm{Na}^{+}$during ionization, resulting in increased mass in the spectra [53]. Therefore, the MS results verified successful coupling of ARP to the AP sites in Oligo 3 and Oligo 4.

Fig. 2 shows PAGE images of Oligo 1 and Oligo 4 after different treatments. For Oligo 1, incubation with UDG alone or UDG and ARP did not lead to any change in the gel image, indicating no reaction had taken place. For Oligo 4, however, the band position moved down slightly after its incubation with UDG (lane 5), due to uracil depyrimidination. In the presence of both UDG and ARP, the original band disappeared, and two new bands emerged that lag behind the original one (lane 6). The new bands are indicative of successful reaction of ARP with the AP site. AP sites exist in one of the three different forms (open-chain aldehyde, hemiacetal and hydrate) in equilibrium. Among these three forms, the aldehyde only represents $1 \%$ of the total. Therefore, incomplete reaction between ARP and the three AP sites in Oligo 4 is expected [54], which might explain the observation of two new bands in the PAGE image. The PAGE results further verified successful biotinylation of the AP sites by ARP. 


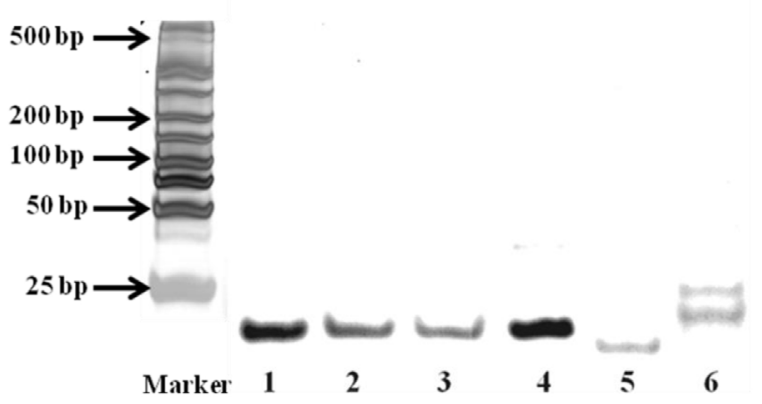

Fig. 2. Nondenaturing PAGE images of $2.0 \mu \mathrm{M}$ Oligo 1 after reacting in (1) $20 \mathrm{mM}$ tris- $\mathrm{HCl}$ (pH 7.4), (2) $5 \mathrm{U} / \mu \mathrm{L}$ UDG, (3) $5 \mathrm{U} / \mu \mathrm{L}$ UDG and $10 \mathrm{mM}$ ARP, and nondenaturing PAGE images of $2.0 \mu \mathrm{M}$ Oligo 4 after reacting in (4) $20 \mathrm{mM}$ tris- $\mathrm{HCl}$ ( $\mathrm{pH} 7.4$ ), (5) $5 \mathrm{U} / \mu \mathrm{L}$ UDG, (6) $5 \mathrm{U} / \mu \mathrm{L}$ UDG and $10 \mathrm{mM}$ ARP.

\subsection{ECL quantification of AP sites in DNA monolayer}

Once the AP site in DNA monolayer is tagged with biotin through ARP, it can be labeled with an ECL signal reporter by reacting with streptavidin-Ru. ECL signal is then measured to quantify the AP site. In Fig. 3A, a Duplex 3-modified electrode displayed an ECL intensity of 2.4 at a peak potential of $1.0 \mathrm{~V}$ after sequential reactions with UDG, ARP and streptavidin-Ru. If any of these reactions was omitted, ECL response was negligible. In Fig. 3B, ECL response of Duplex 1 and Duplex 3 was compared. Duplex 3 produced an ECL signal that was 30 times higher than Duplex 1, demonstrating high selectivity of the ARP tag for AP sites. The relative standard deviation (RSD) of the ECL intensity for Duplex 3-modified electrodes was $5.3 \%$, and the value for Duplex 1 -modified electrodes was $1.8 \%$, demonstrating good reproducibility of the biosensor.

The ECL intensity was found to be highly dependent on the amount of AP sites on the electrode surface. Keeping the total DNA concentration constant $(2.0 \mu \mathrm{M})$, a series of mixture solutions containing different ratios of Duplex 1 and Duplex 3 were prepared for DNA immobilization. As the total DNA concentration in solution was fixed, the surface density of DNA immobilized on the gold electrode was assumed to be the same even when the ratio of the two duplexes was varied. Increasing the fraction of Duplex 1 in the mixture should therefore reduce the surface coverage of Duplex 3, and consequently the number of AP sites. As illustrated in Fig. 4, ECL intensity decreased progressively as Duplex 3 in the mixture solution was diluted with Duplex 1. The ECL peak potential shifted slightly as the surface coverage of AP sites was increased. This may be due to the change of electrochemical oxidation kinetics. Therefore, the maximum ECL was used as signal

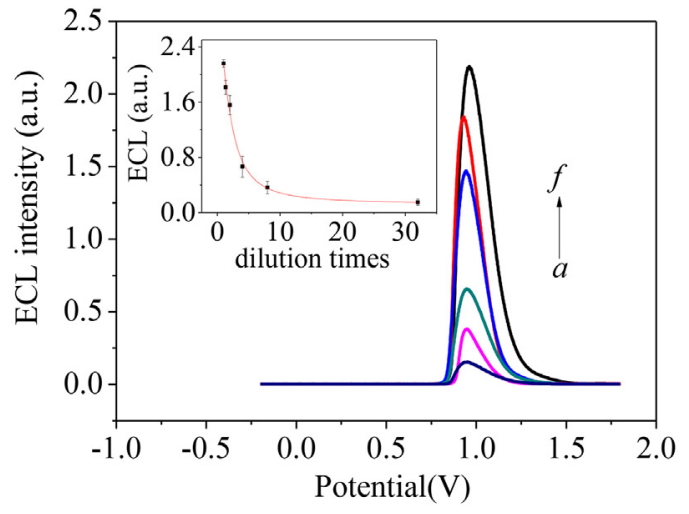

Fig. 4. ECL response curves of gold electrodes modified in a mixture solution containing different ratios of Duplex 3 and Duplex 1, and then reacted sequentially with UDG, ARP, and streptavidin-Ru. The dilution ratio of Duplex 3 by Duplex 1 is $(a) 32$, (b) $8,(c) 4,(d) 2$, (e) 1.3 , and $(f)$ no dilution. Each data point in the inset curve is the mean of three replicates.

readout, not ECL at a fixed potential. At 32 times dilution ratio, the signal was still above the background, which corresponds to a detection limit of 1 AP base in 512 normal bases. Using a DNA surface density of $2.89 \times 10^{-12} \mathrm{~mol} / \mathrm{cm}^{2}$ obtained above and a surface area of $3.14 \times 10^{-2} \mathrm{~cm}^{2}$ for the gold electrode, the detection limit was calculated to be $2.8 \mathrm{fmol}$ AP bases. In previous ARP-based fluorescence and colorimetric assays, the detection limit was estimated to be approximately $1-2$ AP sites per $10^{4}$ nucleotides $[16,21,22]$, which was not independently verified by LC-MS. Because $70 \mathrm{ng}$ DNA sample was used in the assay, the detection limit translates to about 15 fmol AP sites [16]. The sensitivity of our ECL sensor is significantly higher than the fluorescence and colorimetric assays, and is also slightly higher than the value of LC-MS/MS method (6.5 fmol) [55].

As mentioned in the Introduction, various forms of DNA damage usually occur simultaneously, which include strand breaks, base oxidation, AP site generation, and base modification. It is highly desirable for a biosensor to recognize a specific DNA damage among various forms. The selectivity of the current ECL biosensor was evaluated in the following experiment. Duplex G (a duplex containing base oxidation product 8-oxodGuo) was synthesized and immobilized on gold electrodes according to our previous work [31]. The concentration of 8-oxodGuo in Duplex $G$ was 1.67 times higher than the concentration of AP sites in Duplex 3. Methyladenines (metAde) were obtained by reacting a Duplex 1 -modified gold electrode with MMS, a DNA methylating agent [30]. The concentration of metAde in MMS induced Duplex 1 was 3 times higher than the concentra-
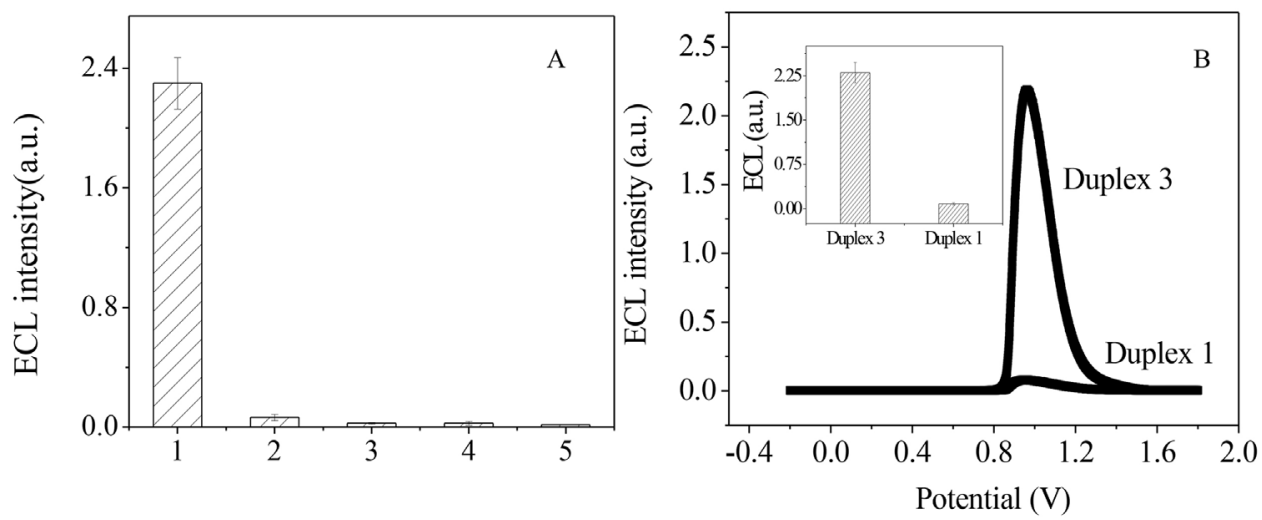

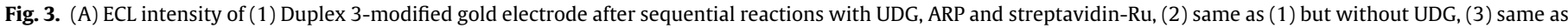

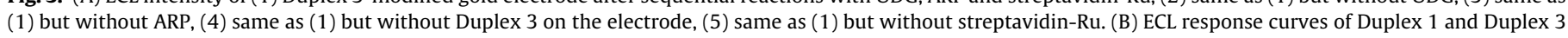
modified electrodes after sequential reactions with UDG, ARP, and streptavidin-Ru. Error bar $=\operatorname{RSD}(n=5)$. 


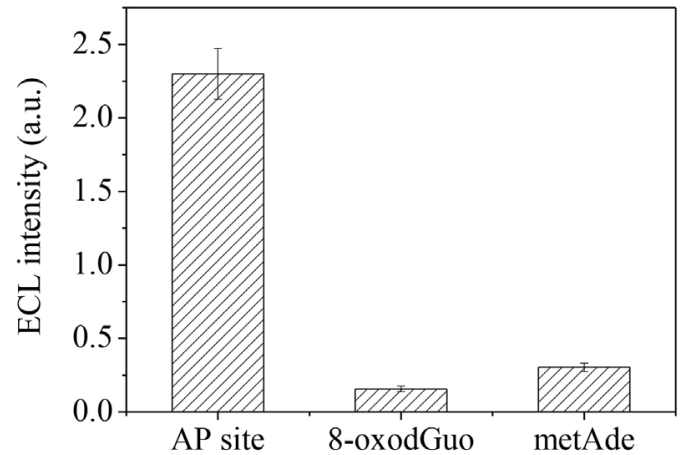

Fig. 5. The bar chart representing selectivity of biosensor for the detection of dsDNA. Each value is mean of three replicates.

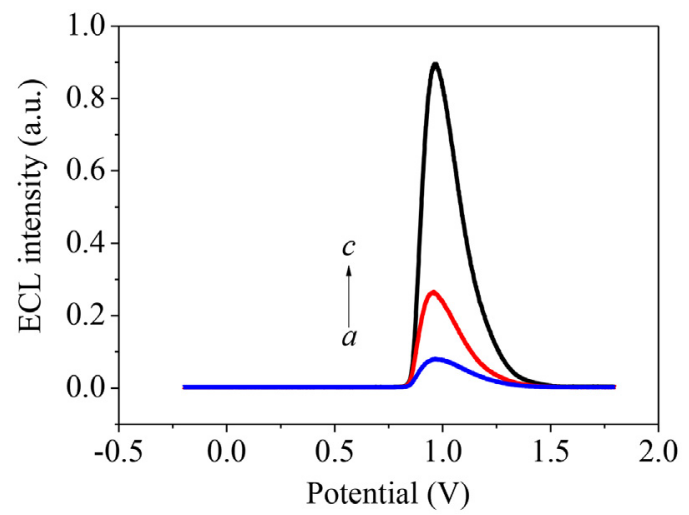

Fig. 6. ECL response curves of Duplex 1 labeled with ARP and streptavidin-Ru after one of the following treatments, (a) blank, (b) $5 \mathrm{mM}$ MMS, and (c) $5 \mathrm{mM}$ MMS and $0.25 \mathrm{U} / \mu \mathrm{L}$ hAAG.

tion of AP sites in Duplex 3. The two electrodes were then measured by the same protocol as AP sites. As shown in Fig. 5, ECL signal of Duplex G-modified electrode was only $7.4 \%$ of Duplex 3, and that of the metAde-containing electrode was $13 \%$. Obviously, the ARP-based biosensor detects selectively the AP sites in DNA films.

\subsection{Detection of chemical-induced AP sites}

To demonstrate the utility of this sensor in the screening of chemicals which might induce AP sites in DNA and are thus potentially genetically toxic, the following experiment was performed. A Duplex 1-modified electrode (containing all normal DNA bases and no uracil) was first exposed to MMS, a known carcinogenic chemical [56]. During the reaction, MMS would methylate some of the DNA bases. In the meantime, spontaneous loss of a few DNA bases would also occur [57]. After the chemical reaction, the electrode was incubated with hAAG, a DNA repairing enzyme which excises alkylated purines from DNA to form AP sites [58]. As expected, the ECL signal increased by about 3 times after MMS reaction, in response to the spontaneous generation of AP sites. And the signal increased by another 3 fold after the enzyme reaction in which more AP sites were generated (Fig. 6).

\section{Conclusions}

To conclude, a novel chemical toxicity sensor was developed based on the ECL detection of AP sites in DNA films. The sensor employs ARP as a covalent biotinylation tag of AP sites, thus offering significantly improved affinity and selectivity over non-covalent probes. Due to its intrinsically high sensitivity, ECL detection of the biotin-tagged AP bases down to $8.5 \mathrm{fmol}$ was achieved on the elec- trode surface. In addition, ECL measurements are typically low cost, simple to operate, and not time-consuming. The novel combination of covalent probe and ECL measurement in a sensor configuration therefore provides unique advantages in terms of selectivity, sensitivity, speed, and simplicity. Combined with the two methods we developed previously for the selective detection of 8-oxodGuo and metAde [29-31], the sensor can be configured into a microplate format for the simultaneous detection of three different types of DNA damage products, as well as for the rapid screening of genetic toxicity of industrial, pharmaceutical and environmental chemicals.

\section{Acknowledgments}

This work was supported by the Chinese Academy of Sciences (XDB14040100) and National Natural Science Foundation of China (21375143, 21621064, 91543203, 21527901).

\section{Appendix A. Supplementary data}

Supplementary data associated with this article can be found, in the online version, at http://dx.doi.org/10.1016/j.snb.2017.04.015.

\section{References}

[1] N.J. Greco, Y. Tor, Simple fluorescent pyrimidine analogues detect the presence of DNA abasic sites, J. Am. Chem. Soc. 127 (2005) 10784-10785.

[2] L.A. Loeb, B.D. Preston, Mutagenesis by apurinic/apyrimidinic sites, Ann. Rev. Genet. 20 (1986) 201-230.

[3] K. Miaskiewicz, R. Osman, Theoretical study on the deoxyribose radicals formed by hydrogen abstraction, J. Am. Chem. Soc. 116 (1994) 232-238.

[4] T. Lindahl, B. Nyberg, Rate of depurination of native deoxyribonucleic acid, Biochemistry 11 (1972) 3610-3618.

[5] S. Boiteux, M. Guillet, Abasic sites in DNA: repair and biological consequences in Saccharomyces cerevisiae, DNA Repair 3 (2004) 1-12.

[6] M.J. Li, Y.P. Wu, B.T. Zhang, L.-H. Guo, Detection and application of DNA abasic sites, Chin. J. Anal. Chem. 41 (2013) 965-972.

[7] H.A. Dahlmann, V.G. Vaidyanathan, S.J. Sturla, Investigating the biochemical impact of DNA damage with structure-based probes: abasic sites, photodimers, alkylation adducts, and oxidative lesions, Biochemistry 48 (2009) 9347-9359.

[8] S. Nishizawa, Y. Sato, N. Teramae, Recent progress in abasic site-binding small molecules for detecting single-base mutations in DNA, Anal. Sci. 30 (2014) 137-142.

[9] K. Yoshimoto, S. Nishizawa, M. Minagawa, N. Teramae, Use of abasic site-containing DNA strands for nucleobase recognition in water, J. Am. Chem. Soc. 125 (2003) 8982-8983.

[10] K. Yoshimoto, C.Y. Xu, S. Nishizawa, T. Haga, H.N. Satake Teramae, Fluorescence detection of guanine-adenine transition by a hydrogen bond forming small compound, Chem. Commun. (2003) 2960-2961.

[11] K. Morita, Y. Sato, T. Seino, S. Nishizawa, N. Teramae, Fluorescence and electrochemical detection of pyrimidine/purine transversion by a ferrocenyl aminonaphthyridine derivative, Org. Biomol. Chem. 6 (2008) 266-268.

[12] Y. Sato, Y. Zhang, T. Seino, T. Sugimoto, S. Nishizawa, N. Teramae, Highly selective binding of naphthyridine with a trifluoromethyl group to cytosine opposite an abasic site in DNA duplexes, Org. Biomol. Chem. 10 (2012) 4003-4006.

[13] Y. Sato, T. Ichihashi, S. Nishizawa, N. Teramae, Strong and selective binding of amiloride to an abasic site in RNA duplexes: thermodynamic characterization and microRNA detection, Angew. Chem. Int. Edit. 51 (2012) 6369-6372.

[14] C.X. Wang, Y. Sato, M. Kudo, S. Nishizawa, N. Teramae, Ratiometric fluorescent signaling of small molecule, environmentally sensitive dye conjugates for detecting single-base mutations in DNA, Chem. Eur. J. 18 (2012) 9481-9484

[15] F. Wu, Y. Sun, Y. Shao, S. Xu, G. Liu, J. Peng, L. Liu, DNA abasic site-selective enhancement of sanguinarine fluorescence with a large emission shift, PLoS One 7 (2012) e48251.

[16] K. Kubo, H. Ide, S.S. Wallace, Y.W. Kow, A novel, sensitive, and specific assay for abasic sites the most commonly produced DNA lesion, Biochemistry 31 (1992) 3703-3708.

[17] H. Atamna, I. Cheung, B.N. Ames, A method for detecting abasic sites in living cells: age-dependent changes in base excision repair, Proc. Natl. Acad. Sci. U. S. A. 97 (2000) 686-691.

[18] M. Tanaka, H. Song, P.A. Kupfer, C.J. Leumann, W.E. Sonntag, An assay for RNA oxidation induced abasic sites using the Aldehyde Reactive Probe, Free Radic. Res. 45 (2011) 237-247.

[19] N. Kojima, T. Takebayashi, A. Mikami, E. Ohtsuka, Y. Komatsu, Construction of highly reactive probes for abasic site detection by introduction of an aromatic and a guanidine residue into an aminooxy group, J. Am. Chem. Soc. 131 (2009) 13208-13209. 
[20] D. Boturyn, A. Boudali, J.F. Constant, E. Defrancq, J. Lhomme, Synthesis of fluorescent probes for the detection of abasic sites in DNA, Tetrahedron 53 (1997) 5485-5492.

[21] M. Adamczyk, P.G. Mattingly, J.A. Moore, O-(fluoresceinylmethyl) hydroxylamine (OFMHA): a fluorescent reagent for detection of damaged nucleic acids, Bioorg. Med. Chem. Lett. 8 (1998) 3599-3602.

[22] D. Boturyn, G.F. Constant, E. Defrancq, J. Lhomme, A. Barbin, C.P. Wild, A simple and sensitive method for in vitro quantitation of abasic sites in DNA, Chem. Res. Toxicol. 12 (1999) 476-482.

[23] M. Bartosk, V. Gajdos, P. Kostecka, M. Fojta, E. Palecek, E. Volkov, T. Oretskaya, T. Hianik, Detection of abasic sites in DNA by electrochemical, immunoelectrochemical and acoustic methods using $\mathrm{OsO}_{4}, 2$, 2'-bipyridine as a probe for unpaired thymine residues, Electroanal 21 (2009) 295-302.

[24] B. Wang J.F. Rusling, Voltammetric sensor for chemical toxicity using $\left.\left.\left[\mathrm{Ru}(\text { bpy })_{2} \text { Poly-(4-Vinylpyridine }\right)_{10} \mathrm{Cl}\right)\right]^{+}$as catalyst in ultrathin films. DNA damage from methylating agents and an enzyme-generated epoxide, Anal. Chem. 75 (2003) 4229-4235.

[25] J. Yang, B. Wang, J.F. Rusling, Genotoxicity sensor response correlated with DNA nucleobase damage rates measured by LC-MS, Mol. Biosyst. 1 (2005) $251-259$.

[26] J.F. Rusling, E.G. Hvastkovs, J.B. Schenkman, Toxicity screening using biosensors that measure DNA damage, Curr. Opin. Drug Disc. 10 (2007) 67-73.

[27] M. Liang, L.-H. Guo, Photoelectrochemical DNA sensor for the rapid detection of DNA damage induced by styrene oxide and the fenton reaction, Environ. Sci. Technol. 41 (2007) 658-664.

[28] M. Liang, S. Jia, S. Zhu, L.-H. Guo, Photoelectrochemical sensor for the rapid detection of in situ DNA damage induced by enzyme-catalyzed fenton reaction, Environ. Sci. Technol. 42 (2008) 635-639.

[29] B. Zhang, L.-H. Guo, M.M. Greenberg, Quantification of 8-OxodGuo lesions in double-stranded DNA using a photoelectrochemical DNA sensor, Anal. Chem 84 (2012) 6048-6053.

[30] Y. Wu, B. Zhang L.-H. Guo, Label-free and selective photoelectrochemical detection of chemical DNA methylation damage using DNA repair enzymes, Anal. Chem. 85 (2013) 6908-6914.

[31] Y. Wu, X. Yang, B. Zhang, L.-H. Guo, An electrochemiluminescence biosensor for 8-oxo-7,8-dihydro-2'-deoxyguanosine quantification and DNA repair enzyme activity analysis using a novel bifunctional probe, Biosens. Bioelectron. 69 (2015) 235-240.

[32] Z. Guo, X. Liu, Y. Liu, G. Wu, X. Lu, Constructing a novel 8-hydroxy-2'-deoxyguanosine electrochemical sensor and application in evaluating the oxidative damages of DNA and guanine, Biosens. Bioelectron. 86 (2016) 671-676.

[33] I. Bist, B. Song, I.M. Mosa, T.E. Keyes, A. Martin, R.J. Forster, J.F. Rusling, Electrochemiluminescent array to detect oxidative damage in dsDNA using $\left[\mathrm{Os}(\mathrm{bpy})_{2} \text { (phen-benz-COOH) }\right]^{2+} /$ Nafion/Graphene films, ACS Sens. 1 (2016) 272-278.

[34] X. Lin, Y. Nia, S. Kokot, An electrochemical DNA-sensor developed with the use of methylene blue as a redox indicator for the detection of DNA damage induced by endocrine-disrupting compounds, Anal. Chim. Acta 867 (2015) 29-37.

[35] M. Fojta, A. Daňhel, L. Havran, V. Vyskočil, Recent progress in electrochemical sensors and assays for DNA damage and repair, Trac-Trends Anal. Chem. 79 (2016) 160-167.

[36] J. Han, Y. Zhuo, Y.Q. Chai, Y. Xiang, R. Yuan, Y.L. Yuan, N. Liao, Ultrasensitive electrochemical strategy for trace detection of APE-1 via triple signal amplification strategy, Biosens. Bioelectron. 41 (2013) 116-122.

[37] W. Miao, Electrogenerated chemiluminescence and its biorelated applications, Chem. Rev. 108 (2008) 2506-2553.

[38] L. Hu, G. Xu, Chem. Applications and trends in electrochemiluminescence, Soc. Rev. 39 (2010) 3275-3304.

[39] M. Liang, S. Liu, M. Wei, L.-H. Guo, Photoelectrochemical oxidation of DNA by ruthenium tris(bipyridine) on a tin oxide nanoparticle electrode, Anal. Chem. 78 (2006) 621-623.

[40] D. Dong, D. Zheng, F.-Q. Wang, X.-Q. Yang, N. Wang, Y.-G. Li, L.-H. Guo, J. Cheng, Quantitative photoelectrochemical detection of biological affinity reaction: biotin-Avidin interaction, Anal. Chem. 76 (2004) 499-501.

[41] J. Zhang, S. Song, L. Wang, D. Pan, C. Fan, A gold nanoparticle-based chronocoulometric DNA sensor for amplified detection of DNA, Nat. Protoc. 2 (2007) 2888-2895.

[42] H. Krokan, Preferential association of uracil-DNA glycosylase activity with replicating SV40 minichromosomes, FEBS Lett. 133 (1981) 89-91.

[43] R.H. Porecha, J.T. Stivers, Uracil DNA glycosylase uses DNA hopping and short-range sliding to trap extrahelical uracils, Proc. Natl. Acad. Sci. U. S. A. 105 (2008) 10791-10796.
[44] C. Lin, S. Rinker, X. Wang, Y. Liu, N.C. Seeman, H. Yan, In vivo cloning of artificial DNA nanostructures, Proc. Natl. Acad. Sci. U. S. A. 105 (2008) $17626-17631$

[45] C. Zhao, R. Yin, J. Yin, D. Zhang, H. Wang, Capillary monolithic bioreactor of immobilized snake venom phosphodiesterase for mass spectrometry based oligodeoxynucleotide sequencing, Anal. Chem. 84 (2012) 1157-1164.

[46] Q. Fan, J. Zhao, H. Li, L. Zhu, G. Li, Exonuclease III-based and gold nanoparticle-assisted DNA detection with dual signal amplification, Biosens. Bioelectron. 33 (2012) 211-215.

[47] R. Levicky, T.M. Herne, M.J. Tarlov, S.K. Satija, Using self-assembly to control the structure of DNA monolayers on gold: a neutron reflectivity study, J. Am. Chem. Soc. 120 (1998) 9787-9792.

[48] G. Liang, T. Li, X. Li, X. Liu, Electrochemical detection of the amino-substituted naphthalene compounds based on intercalative interaction with hairpin DNA Ćby electrochemical impedance spectroscopy, Biosens. Bioelectron. 48 (2013) 238-243.

[49] A.B. Steel, T.M. Herne, M.J. Tarlov, Electrochemical quantitation of DNA immobilized on gold, Anal. Chem. 70 (1998) 4670-4677.

[50] J. Zhang, S. Song, L. Zhang, L. Wang, H. Wu, D. Pan, C. Fan, Sequence-specific detection of femtomolar DNA via a chronocoulometric DNA sensor (CDS): effects of nanoparticle-mediated amplification and nanoscale control of DNA assembly at electrodes, J. Am. Chem. Soc. 128 (2006) 8575-8580.

[51] R. Shapiro, B. Braverman, J.B. Louis, R.E. Servis, Nucleic acid reactivity and conformation, J. Biol. Chem. 248 (1973) 4060-4064

[52] R.H. Porecha, J.T. Stivers, Uracil DNA glycosylase uses DNA hopping and short-range sliding to trap extrahelical uracils, Proc. Natl. Acad. Sci. U. S. A. 105 (2008) 10791-10796.

[53] J.A. Ragas, T.A. Simmons, P.A. Limbach, A comparative study on methods of optimal sample preparation for the analysis of oligonucleotides by matrix-assisted laser desorption/ionization mass spectrometry, Analyst 125 (2000) 575-581.

[54] J. Lhomme, J.F. Constant, M. Demeunynck, Abasic DNA structure, reactivity, and recognition, Biopolymers 52 (1999) 65-83.

[55] J. Li, E. Leung, M. Choi, W. Chan, Combination of pentafluorophenylhydrazine derivatization and isotope dilution LC-MS/MS techniques for the quantification of apurinic/apyrimidinic sites in cellular DNA, Anal. Bioanal. Chem. 405 (2013) 4059-4066.

[56] S.H. Doak, G.J. Jenkins, G.E. Johnson, E. Quick, E.M. Parry, J.M. Parry, Mechanistic influences for mutation induction curves after exposure to DNA-reactive carcinogens, Cancer Res. 67 (2007) 3904-3911.

[57] K. Ezaz-Nikpay, G.L. Verdine, The effects of $\mathrm{N}_{7}$-methylguanine on duplex DNA structure, Chem. Biol. 1 (1994) 235-240.

[58] J. Klapacz, G.M. Lingaraju, H.H. Guo, D. Shah, A. Moar-Shoshani, L.A. Loeb, L.D. Samson, Frameshift mutagenesis and microsatellite instability induced by human alkyladenine DNA glycosylase, Mol. Cell 37 (2010) 843-853.

\section{Biographies}

Rui Feng is pursuing her PhD degree at Research Center for Eco-environmental Science, Chinese Academy of Sciences, and University of the Chinese Academy of Sciences. Research interests: the development of novel electrochemiluminescence sensors for DNA damage detection.

Gang Liang received his $\mathrm{PhD}$ degree in Environmental Science from Beijing Normal University in 2013. He completed his post-doctoral research at Research Center for Eco-environmental Science, Chinese Academy of Sciences, and University of the Chinese Academy of Sciences in 2015. Now, he is working at Beijing Research Center for Agricultural Standards and Testing, Beijing Academy of Agricuture and Forestry Science as an Associate Professor. Current research interests: Environmental bioanalysis and electrode biosensing.

Liang-Hong Guo, Principal Investigator at Research Center for Eco-environmental Science, Chinese Academy of Sciences, and Professor of the University of the Chinese Academy of Sciences. Major research interests: biosensors and bioassays for environmental contaminants, environmental molecular toxicology.

Yi-Ping Wu received her PhD degree at Research Center for Eco-environmental Science, Chinese Academy of Sciences, and University of the Chinese Academy of Sciences in 2014. Now, she is a Lecturer at Shanghai Normal University. Current research interests: construction of electrochemical sensor and its application in environmental testing. 